\title{
Comparison of Arterial Stiffness Parameters in Patients With Coronary Artery Disease and Diabetes Mellitus Using Arteriograph
}

\author{
Z. LENKEY ${ }^{1}$, M. ILLYÉS ${ }^{1}$, R. BÖCSKEI ${ }^{1}$, R. HUSZNAI ${ }^{1}$, Z. SÁRSZEGI ${ }^{1}$, \\ Z. MEISZTERICS ${ }^{1}$, F. T. MOLNÁR ${ }^{2}$, G. HILD $^{3}$, S. SZABADOS $^{1}$, A. CZIRÁKI $^{1}$, \\ B. GASZNER ${ }^{1^{*}}$ \\ * The last two authors contributed equally.
}

${ }^{1}$ Heart Institute, Medical School, University of Pécs, Pécs, Hungary, ${ }^{2}$ Department of Hydrodynamic Systems, Budapest University of Technology and Economics, Budapest, Hungary, ${ }^{3}$ Department of Biophysics, Medical School, University of Pécs, Pécs, Hungary

Received February 5, 2013

Accepted January 10, 2014

On-line April 3, 2014

\section{Summary}

Recently an expert consensus document advised to standardize user procedures and a new cut-off value for carotid-femoral pulse wave velocity in daily practice. Our aim was to observe aortic pulse wave velocity (PWVao) and augmentation index (AIXao) in two high cardiovascular risk groups: patients with verified coronary artery disease (CAD) or with type 2 diabetes mellitus (T2DM). We also aimed to determine the cut-off values for PWVao, AIXao in CAD and T2DM patients using oscillometric device (Arteriograph). We investigated 186 CAD and 152 T2DM patients. PWVao and AIXao increased significantly in the CAD group compared to the age-, gender-, blood pressure-, and heart rate-matched control group $(10.2 \pm 2.3$ vs. $9.3 \pm 1.5 \mathrm{~m} / \mathrm{s}$; $\mathrm{p}<0.001$ and $34.9 \pm 14.6$ vs. $31.9 \pm 12.8 \%$; $<<0.05$, respectively). When compared to the apparently healthy control subjects, T2DM patients had significantly elevated PWVao ( $9.7 \pm 1.7$ vs. $9.3 \pm 1.5 \mathrm{~m} / \mathrm{s} ; \mathrm{p}<0.05$, respectively), however the AIXao did not differ significantly. The ROC-curves of CAD and healthy control subjects explored cut-off values of $10.2 \mathrm{~m} / \mathrm{s}$ for PWVao and $33.23 \%$ for AIXao. Our data provide supporting evidence about impaired arterial stiffness parameters in CAD and T2DM. Our findings encourage the implementation of arterial stiffness measurements by oscillometric method in daily clinical routine.

\section{Key words}

Coronary heart disease • Diabetes mellitus • Arterial stiffness • Cut-off value

\section{Corresponding author}

B. Gaszner, Heart Institute, Medical School, University of Pécs, Ifjúság str. 13, H-7624 Pécs, Hungary. E-mail: balazs.gaszner@ aok.pte.hu

\section{Introduction}

Investigation of aortic stiffness measured as aortic pulse wave velocity (PWVao) and augmentation index (AIXao) has become increasingly important for total cardiovascular $(\mathrm{CV})$ risk estimation in patients with verified coronary artery disease (Laurent et al. 2001, Boutouyrie et al. 2002, Hansson 2005, Najjar et al. 2005, Mattace-Raso et al. 2006, D’Agostino et al. 2008). Type 2 diabetes mellitus is also known to carry high CV risk like patients with prior CV disease (Haffner et al. 1998). The 2012 Joint European Society guidelines on CV disease prevention recommended that patients with DM and the existence of target organ damage should be considered to be at very high risk. Detection of arterial stiffness by pulse wave velocity may be considered as useful cardiovascular marker, adding predictive value to the CV risk estimation. Therefore the assessment of PWV as a target organ damage marker should be an important part of ambulatory risk stratification in coronary artery disease patients and patients with type 2 diabetes mellitus. During the last decade, among the stiffness parameters the carotid-femoral PWV has become widely accepted for total CV risk estimation (Laurent et al. 2006, 
Willum-Hansen et al. 2006). For clinical patient evaluation the Reference Values for Arterial Stiffness Collaboration Group established reference and normal values for PWV based on a large European population (Reference Values for Arterial Stiffness' Collaboration 2010). Arterial stiffness is not uniform in patients with T2DM yielding inconsistent results about changes in AIX. Thus previous studies suggested different clinical significance of AIX and PWV (the gold standard measurement of arterial stiffness) in T2DM (Lacy et al. 2004, Ogawa et al. 2008, Zhang et al. 2011). The association between AIX and PWV in T2DM is weakly understood.

Several different methodologies have been proposed to the assessment of arterial stiffness. However, the application of stiffness parameters as a routine tool for clinical patient evaluation has been hampered due to the lack of standardization of different measurement techniques. For this reason comparison of the techniques (Arteriograph, Complior, SphygmoCor) was established in hypertensive patients. Although appropriate agreement for PWV and AIX has been found between the oscillometric (Arteriograph) and the common used tonometric (SphygmoCor), piezoelectronic (Complior) devices, it has also been emphasized that data of the three techniques are not interchangeable (Baulmann et al. 2008, Jatoi et al. 2009, Boutouyrie et al. 2009).

Recently an expert consensus recommendation for the measurement of aortic stiffness has been published (Van Bortel et al. 2012). The researcher group suggested standardizing user procedures and the use of $10 \mathrm{~m} / \mathrm{s}$ as cut-off value for carotid-femoral pulse wave velocity in the prediction of cardiovascular events. However, in patients with high cardiovascular risk scarce data on the prognostic value of aortic stiffness parameters are available for regional pulse wave analyzer equipments.

Arteriograph is an oscillometric, occlusive method that has been invasively validated by our researcher group and become available for the clinically feasible detection of regional arterial stiffness (Horváth et al. 2010). In our study we aimed to compare arterial stiffness parameters (PWVao and AIXao) between two high cardiovascular risk groups: patients with verified coronary artery disease (CAD) or with type 2 diabetes mellitus (T2DM), using Arteriograph device. We also aimed to determine the cut-off values for PWVao, AIXao; and to calculate the sensitivity and specificity of arterial stiffness parameters in verified CAD and T2DM.

\section{Materials and Methods}

\section{Arterial stiffness measurements}

For the evaluation of arterial stiffness parameters, a total of 524 patients were studied. Exclusion criteria were arrhythmia, valvular heart disorders, renal failure, peripheral artery disease and heart failure (New York Heart Association criteria III-IV). We performed elective coronary angiography in 186 consecutive patients who were referred to the Department of Invasive Cardiology of our hospital. All patients had previous concordant noninvasive findings for CAD and had experienced angina pectoris. In the T2DM group the measurements were performed during the routine check-up. Control subjects were measured during a routine health screening examination. The simultaneous measurements of AIXao, PWVao and brachial blood pressure were carried out within 3-4 min with the oscillometric, occlusive device (Arteriograph, TensioMed, Budapest, Hungary). This method is based on the complete occlusion of the brachial artery by a simple cuff, which allows the recording and separation of pronounced early (forward) and late (reflected) systolic waves. The time elapsed between the early and late systolic wave peaks equals the travel time of the forward aortic pulse wave to the bifurcation and its backward reflection to the observational site. The sternal notch/pubic bone distance was used to calculate the PWVao (Sugawara et al. 2008). The augmentation index was calculated taking the differences between amplitudes of the forward and reflected systolic waves; the resulting value was divided by the pulse pressure and finally multiplied by 100 . The measurements were performed in a supine position and were accepted if the quality indicator of the recordings was within the acceptable range (i.e. the $\mathrm{SD}$ of the beat-to-beat measured PWVao values was less than $1.1 \mathrm{~m} / \mathrm{s}$ ).

\section{Patients with CAD}

We investigated $186 \mathrm{CAD}$ patients $(61 \pm 9$ years, age range: 40-84 years) and 186 age- and gender-, mean blood pressure and heart rate-matched control subjects, randomly selected from a previously collected database of apparently healthy, medication-free, asymptomatic subjects. The patients' characteristics are shown in Table 1. Smoking status was defined as current or past use of cigarettes. CAD was diagnosed by elective coronary angiography using the Judkins technique on digitized coronary angiography equipment (Integris, 
Philips). For this study, we defined significant CAD as showing at least $50 \%$ or greater stenosis, or at least $75 \%$ or greater flow-reduction in one coronary artery. Patients in the CAD group received appropriate medical treatment (angiotensin-converting enzyme inhibitor, angiotensin II receptor blocker, statins, low-dose aspirin, beta-blockers) according to the relevant guidelines (2013 ESC guidelines on the management of stable coronary artery disease).

\section{Patients with T2DM}

We evaluated 152 patients with T2DM (61 \pm 9 years; age range: $40-82$ years), who were free from known coronary artery disease and were treated with oral anti-diabetic and other (angiotensin-converting enzyme inhibitor, angiotensin II receptor blocker, calcium channel blocker, statins, aspirin) drugs (ESC Guidelines on diabetes, pre-diabetes, and cardiovascular diseases developed in collaboration with the EASD 2013). Diabetes was diagnosed by hemoglobin $A_{1 C}$ level $\geq 6.5 \%$ and fasting plasma glucose $\geq 7.0 \mathrm{mmol} / 1$, or abnormal oral glucose tolerance test (OGTT level after a 2-hour interval is equal or more than $11.1 \mathrm{mmol} / \mathrm{l}$ ) or a previous diagnosis of T2DM. The antidiabetic treatment was monitored with the measurement of serum hemoglobin $\mathrm{A}_{1 \mathrm{C}}$ level.

152 age- and gender-, mean blood pressure and heart rate matched subjects comprised the control group, randomly selected from the previously mentioned large database. Smoking status was also defined as current or past use of cigarettes. The patients' characteristics are shown in Table 1.

\section{Statistical analysis}

The CAD and T2DM populations were matched to healthy counterparts by age, gender, blood pressure and heart rate. CAD-to-diabetic matching was also performed using the same rules. Continuous data are reported as mean $\pm \mathrm{SD}$. The clinical parameters of the matched populations were compared by using the Student's paired $t$-test, with the significance level set at 0.05 . Multiple regression analysis was performed to investigate the relationship between arterial stiffness indices, clinical parameters, and the use of antihypertensive, diabetes, antilipid medications. Discrimination was calculated with the areas under the receiver-operating characteristic (ROC) curves in case of
CAD, T2DM and control subjects for both PWVao and AIXao. An area of 1.0 would indicate perfect discrimination, while 0.5 means the absence of discriminatory power.

\section{Results}

Demographic, clinical, hemodynamic and medication characteristics are summarized in Table 1.

When we compared the CAD group to the age-, gender-, mean blood pressure-, and heart rate-matched, apparently healthy control group we found that PWVao and AIXao values in CAD patients were significantly higher (Table 2). In the T2DM population PWVao was significantly higher compared to the control group, whilst no significant differences were seen in the AIXao. We made comparison with the age-, gender-, mean blood pressure-, and heart rate-matched CAD and T2DM groups, and found non-significant differences in PWVao $(\mathrm{p}=0.10)$ and markedly lower AIXao in the T2DM group $(\mathrm{p}<0.001)$ (Table 2).

The impact of antihypertensive, antilipid, oral antidiabetic medications (ACEI/ARB, beta-blockers, calcium channel antagonists, nitrates, statins, sulfonylureas and metformin) on measures of arterial stiffness were also investigated in our study population. In multiple regression analysis the use of ACEI/ARB was the only significant determinant of the stiffness parameters (Table 3). For beta-blockers, calcium channel antagonists, nitrates, and statins we found improvement in both stiffness indices, however the change in PWV and AIX did not reach the level of significance (data not shown).

The ROC-curves for aortic PWV and AIXao are seen in Figure 1. Statistics explored a cut-off value of $10.2 \mathrm{~m} / \mathrm{s}$ for PWVao and $33.2 \%$ for AIXao in the comparison of $\mathrm{CAD}$ and healthy control subjects with acceptable area under curve (AUC), sensitivity and specificity data (Table 4). In addition, when ROC analysis were performed in CAD patients not receiving ACEI/ARB vs. control subjects significant improvement in sensitivity and specificity were found for PWVao and AIXao $\quad(p<0.05) \quad($ Table 5). ROC analysis revealed acceptable sensitivity and specificity results for PWV at a cut off value of $10.20 \mathrm{~m} / \mathrm{s}(\mathrm{p}<0.05)$ for the analysis of T2DM vs. healthy control subjects (Table 4). 
Table 1. Descriptive statistics of healthy control subjects, patients with known coronary artery disease (CAD), and with type 2 diabetes mellitus (T2DM).

\begin{tabular}{|c|c|c|c|c|c|}
\hline Variable & $\begin{array}{c}\text { Control group } \\
(\mathbf{n}=\mathbf{1 8 6})\end{array}$ & $\begin{array}{c}\text { CAD group } \\
(\mathrm{n}=186)\end{array}$ & p-value & $\begin{array}{l}\text { T2DM group } \\
\quad(\mathrm{n}=152)\end{array}$ & p-value \\
\hline Age (years) & $61 \pm 9$ & $61 \pm 9$ & & $61 \pm 9$ & \\
\hline Male, $n(\%)$ & $138(74)$ & $138(74)$ & & $112(74)$ & \\
\hline Weight (kg) & $81 \pm 15$ & $84 \pm 15$ & 0.050 & $88 \pm 16$ & 0.020 \\
\hline Height $(\mathrm{cm})$ & $171 \pm 9$ & $170 \pm 8$ & 0.379 & $171 \pm 9$ & 0.870 \\
\hline$B M I\left(\mathrm{~kg} / \mathrm{m}^{2}\right)$ & $27.6 \pm 4.1$ & $29.12 \pm 4.28$ & $<0.05$ & $30 \pm 4.5$ & $<0.05$ \\
\hline Smokers, $n(\%)$ & $12(7)$ & $39(21)$ & 0.001 & $18(12)$ & 0.010 \\
\hline$S B P(m m ~ H g)$ & $136.7 \pm 17.0$ & $136.7 \pm 21.2$ & 0.940 & $136.8 \pm 17.4$ & 0.930 \\
\hline$D B P(m m ~ H g)$ & $81.3 \pm 10.1$ & $81.2 \pm 13.1$ & 0.910 & $81.4 \pm 11.5$ & 0.920 \\
\hline$M A P(m m ~ H g)$ & $99.8 \pm 11.5$ & $99.7 \pm 15.4$ & 0.940 & $99.9 \pm 12.0$ & 0.930 \\
\hline HR (beat/min) & $69.2 \pm 11.4$ & $69.1 \pm 12.4$ & 0.900 & $69.3 \pm 10.8$ & 0.940 \\
\hline Hypertension (\%) & 0 & 59 & $<0.001$ & 44 & $<0.001$ \\
\hline Glucose $(\mathrm{mmol} / \mathrm{l})$ & $5.3(4.3-5.9)$ & $5.6(4.2-6.3)$ & 0.390 & $6.9(3.7-9.9)$ & $<0.001$ \\
\hline HbAlc (\%) & & & & $7.1 \pm 1.5$ & \\
\hline Creatinin $(\mu \mathrm{mol} / \mathrm{l})$ & $68.3 \pm 16.5$ & $69.3 \pm 17.5$ & 0.077 & $73.8 \pm 19.5$ & 0.035 \\
\hline eGFR $(\mathrm{ml} / \mathrm{min})$ & $92.3 \pm 21.5$ & $89.3 \pm 20.5$ & 0.067 & $85.9 \pm 24.5$ & 0.020 \\
\hline$T C(\mathrm{mmol} / \mathrm{l})$ & $5.4 \pm 0.9$ & $5.6 \pm 1.2$ & 0.202 & $5.7 \pm 0.8$ & 0.123 \\
\hline$H D L-C(\mathrm{mmol} / \mathrm{l})$ & $1.5 \pm 0.3$ & $1.4 \pm 0.4$ & 0.306 & $1.3 \pm 0.3$ & 0.050 \\
\hline$L D L-C(\mathrm{mmol} / \mathrm{l})$ & $3.3 \pm 0.4$ & $3.5 \pm 0.5$ & 0.060 & $3.6 \pm 0.8$ & 0.020 \\
\hline Triglyceride (mmol/l) & $1.3(0.7-1.8)$ & $1.3(0.8-1.9)$ & 0.522 & $1.6(0.6-2.7)$ & 0.009 \\
\hline \multicolumn{6}{|l|}{ Treatment } \\
\hline$B B(\%)$ & 0 & 76 & $<0.001$ & 48 & $<0.001$ \\
\hline$A C E I / A R B(\%)$ & 0 & 74 & $<0.001$ & 51 & $<0.001$ \\
\hline$A S A(\%)$ & 0 & 80 & $<0.001$ & 19 & $<0.001$ \\
\hline Statins (\%) & 0 & 75 & $<0.001$ & 33 & $<0.001$ \\
\hline$C C B(\%)$ & 0 & 34 & $<0.001$ & 13 & $<0.001$ \\
\hline Nitrate (\%) & 0 & 40 & $<0.001$ & 4 & $<0.005$ \\
\hline Oral antidiabetics (\%) & 0 & 0 & & 68 & \\
\hline
\end{tabular}

Data are presented as mean \pm SD or median, $p$-values for control subjects. SBP: systolic blood pressure; DBP: diastolic blood pressure; MAP: mean arterial pressure; HR: heart rate; eGFR: estimated glomerular filtration rate; TC: total cholesterol; HDL-C: high-density lipoprotein cholesterol; LDL-C: low-density lipoprotein cholesterol; BB: beta blocker; ACEI: angiotensin converting enzyme inhibitor; ARB: angiotensin receptor blocker; CCB: calcium channel blocker.

Table 2. Indices of arterial stiffness in patients with coronary artery disease (CAD), type 2 diabetes mellitus (T2DM) and healthy control subjects.

\begin{tabular}{lccccc}
\hline & $\begin{array}{c}\text { Control group } \\
(\mathbf{n = 1 8 6 )}\end{array}$ & $\begin{array}{c}\text { CAD group } \\
(\mathbf{n = 1 8 6 )}\end{array}$ & p-value & $\begin{array}{c}\text { T2DM group } \\
(\mathbf{n = 1 5 2})\end{array}$ & p-value \\
\hline PWVao $(\mathrm{m} / \mathrm{s})$ & $9.3 \pm 1.5$ & $10.2 \pm 2.3$ & $<0.001$ & $9.7 \pm 1.7$ & $<0.05$ \\
AIXaо $(\%)$ & $31.9 \pm 12.8$ & $34.9 \pm 14.6$ & $<0.05$ & $29.3 \pm 13.0$ & 0.10 \\
\hline
\end{tabular}

Data are presented as mean \pm SD. 
Table 3. Multiple regression analysis of PWVao and AIXao.

\begin{tabular}{lcccc}
\hline Variable & PWVao & PWVao & AIXao & AIXao \\
& $\mathbf{r}$ & $\mathbf{p}$ & $\mathbf{p}$ & $<0.001$ \\
\hline Age & 0.39 & $<0.001$ & 0.26 & $<0.001$ \\
Heart rate & 0.21 & $<0.001$ & -0.35 & 0.35 \\
SBP & 0.41 & $<0.001$ & 0.10 & 0.04 \\
ACEI/ARB & -0.16 & 0.03 & -0.13 & \\
\hline
\end{tabular}

Correlation coefficients of multiple regression $(r)$ and the level of significance are only shown when $p<0.05$. SBP: systolic blood pressure; ACEI/ARB: angiotensin converting enzyme inhibitor/angiotensin receptor blocker.

Table 4. Sensitivity and specificity for cut-off values of arterial stiffness parameters determined by Arteriograph for discriminating coronary artery disease and type 2 diabetes mellitus.

\begin{tabular}{|c|c|c|c|c|c|c|}
\hline \multirow{3}{*}{ Variable } & \multicolumn{4}{|c|}{ CAD group } & \multirow{2}{*}{\multicolumn{2}{|c|}{$\begin{array}{c}\text { T2DM group } \\
\text { PWVao }(\mathbf{m} / \mathbf{s}) * * *\end{array}$}} \\
\hline & \multicolumn{2}{|c|}{$\operatorname{PWVao}(\mathrm{m} / \mathrm{s}) *$} & \multicolumn{2}{|c|}{$\operatorname{AIXao}(\%) * *$} & & \\
\hline & Value & $95 \% \mathrm{CI}$ & Value & $95 \%$ CI & Value & $95 \% \mathrm{CI}$ \\
\hline$A U C$ & 0.61 & $0.54-0.67$ & 0.57 & $0.51-62$ & 0.57 & $0.52-0.61$ \\
\hline Sensitivity & 0.66 & $0.55-0.72$ & 0.58 & $0.50-0.66$ & 0.62 & $0.52-0.7$ \\
\hline Specificity & 0.57 & $0.51-0.66$ & 0.58 & $0.52-0.68$ & 0.55 & $0.51-0.61$ \\
\hline Positive predictive value & 0.65 & $0.56-0.72$ & 0.63 & $0.56-0.69$ & 0.63 & $0.54-0.70$ \\
\hline Negative predictive value & 0.6 & $0.53-0.68$ & 0.61 & $0.55-0.67$ & 0.57 & $0.51-0.65$ \\
\hline Relative risk & 1.53 & $1.2-1.79$ & 1.48 & $1.21-1.89$ & 1.43 & $1.1-1.71$ \\
\hline Odds ratio & 2.30 & $1.4-3.34$ & 2.3 & $1.49-3.54$ & 2.10 & $1.35-3.02$ \\
\hline
\end{tabular}

CI: confidence interval, * cut-off value for PWVao: $10.20 \mathrm{~m} / \mathrm{s}$, ** cut-off value for AIXao: $33.23 \%$, *** cut-off value for PWVao: $10.20 \mathrm{~m} / \mathrm{s}$.

Table 5. Sensitivity and specificity for cut-off values of arterial stiffness parameters determined by Arteriograph for CAD patients not taking ACEI/ARB.

\begin{tabular}{|c|c|c|c|c|}
\hline \multirow[b]{2}{*}{ Variable } & \multicolumn{2}{|c|}{$\operatorname{PWVao}(\mathrm{m} / \mathrm{s})$ * } & \multicolumn{2}{|c|}{$\operatorname{AIXao}(\%) * *$} \\
\hline & Value & $95 \% \mathrm{CI}$ & Value & $95 \% \mathrm{CI}$ \\
\hline$A U C$ & 0.66 & $0.56-0.77$ & 0.60 & $0.51-0.70$ \\
\hline Sensitivity & 0.69 & $0.58-0.74$ & 0.61 & $0.54-0.7$ \\
\hline Specificity & 0.61 & $0.54-0.69$ & 0.61 & $0.54-0.7$ \\
\hline
\end{tabular}

CI: confidence interval, * cut-off value for PWVao: $10.20 \mathrm{~m} / \mathrm{s}, * *$ cut-off value for AIXao: $33.23 \%$.
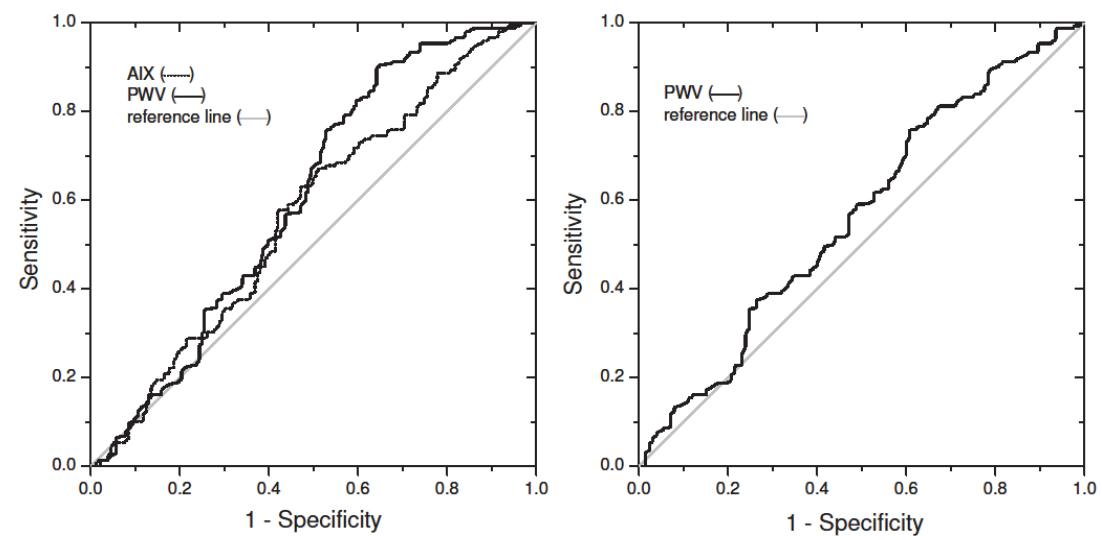

Fig. 1. Receiver-operating characteristic (ROC) curves of the simultaneously recorded aortic augmentation index (AIXao) and pulse wave velocity (PWVao) in case of patients with established coronary artery disease and age-, gender-, mean blood pressure- and heart rate-matched control subjects and ROC curve of the pulse wave velocity (PWVao) in case of patients with T2DM and age-, gender-, mean blood pressure- and heart rate-matched control subjects. 


\section{Discussion}

Comparing the CAD and the age-, gender-, blood pressure-, and heart rate-matched control subjects we found that PWVao and AIXao were significantly higher in the CAD group. Therefore, we can suppose that the significantly higher aortic PWV and AIX values are specifically related to the impaired arterial function in the CAD patients. Our findings are supported by the results of Weber et al. (2004), who also indicated a very strong relationship between the increased aortic AIX and CAD which was proven by coronary angiography. The relationship between coronary atherosclerosis and aortic PWV was elegantly proven by Kullo and co-workers (2006) in a large study assessing the quantity of coronary artery calcium with computed tomography and the aortic PWV with carotid-femoral PWV measurement. The average age of the population studied in their work was very close to ours, thus enhancing comparability with our findings.

Another important observation of our research is that aortic stiffness as measured with PWVao was similarly elevated in the CAD and in the age-, gender-, blood pressure-, and heart rate-matched T2DM group, while T2DM patients showed significantly reduced AIXao when compared to CAD patients. The greatest value of our study is the precise matching of the studied populations that excluded the possible modifying effects of age, gender, blood pressure and heart rate on PWVao and AIXao during the comparison. Taking into consideration that impaired PWVao is the sign of elevated cardiovascular risk, this similarly elevated PWVao could be an evidence that patients with type 2 diabetes mellitus carry as high risk as patients with known ischemic heart disease (Haffner et al. 1998). However the difference in AIXao between the age-, gender-, blood pressure- and heart rate-matched CAD and T2DM patients were striking. The lower value of augmentation index in case of T2DM patients could be explained by the assumption that in several patients with T2DM hyperinsulinemia could exist, which produces increased sympathetic activity and consequently, lowers the AIX. Indeed, Westerbacka and co-workers (2000) pointed out that insulin infusion significantly decreases the AIXao. Our findings are in agreement with the results of Lacy and co-workers (2004). In their study cohort comprising T2DM and control subjects they found significant difference between the aortic PWV values and no change in the AIXao results, which could be explained by the above mentioned hyperinsulinemia (Westerbacka et al. 2000). Zhang et al. (2011) pointed out that stiffness of both central and peripheral arteries are increased, but augmentation index is preserved in Chinese patients with T2DM when compared to healthy control subjects. Khoshdel and Carney (2005) indicated that because of the wider pulse pressure (PP) observed in diabetics, PP is the major determinant of AIX in this patient population. The dependence of the wider PP on other factors, such as arterial stiffness and cardiac contractility results in the underestimation of AIX that reduces the validity of AIX in case of DM patients. Ogawa and coworkers (2008) examined 201 patients with T2DM and investigated the relationship between arterial stiffness parameters and diabetic retinopathy. They concluded that only PWV correlated with the presence of diabetic retinopathy, but not AIX which may indicate that chronic hyperglycemia and the duration of diabetes mellitus may not be associated with AIX. Furthermore, we cannot exclude the potential effects of the applied drugs on the AIXao, since several studies showed the beneficial effects of ACEI/ARB, statins, CCB and vasodilatator BB on AIXao and PWVao (Mallareddy et al. 2006, Mahmud and Feely 2008, Manisty et al. 2009, Doi et al. 2010, Boutouyrie et al. 2011). According to our results the use of ACEI/ARB was a significant determinant of the stiffness parameters. Our data suggest that pharmacological modulation of the stiffness parameters could also explain the relatively lower AIXao data in the T2DM group.

The ROC analysis in our CAD patient study population advices to use $10.2 \mathrm{~m} / \mathrm{s}$ as the cut-off value for regional aortic pulse wave velocity. Our finding precisely matches the new recommendation of carotid-femoral PWV (cfPWV) recording (Van Bortel et al. 2012), suggesting that the pulse wave analyzer Arteriograph measured PWVao is close to the cfPWV value as it is pointed out by other studies (Baulmann et al. 2008, Jatoi et al. 2009). The sensitivity and specificity results for the Arteriograph are in the acceptable range, however the above mentioned confounding effect of the antihypertensive, antilipid, and oral antidiabetic drugs applied in the CAD, T2DM groups could explain this apparent controversy (Boutouyrie et al. 2011). Our study proved the pharmacological modulation of the stiffness parameters for $\mathrm{ACEI} / \mathrm{ARB}$, resulting in decrease for PWVao and AIX. However for this purpose a longitudinal study for the Arteriograph would be preferable in the future. 


\section{Conclusion}

In our study we applied a simple, feasible oscillometric method. We have revealed a significant impairment of arterial stiffness, measured as increased PWVao in patients with CAD and T2DM, which reflects premature arterial damage. The cut-off value for PWVao measured by Arteriograph is in good correlation with the recently published recommendation of cfPWV recording. However, the clinical significance of AIXao as a useful vascular stiffness marker in T2DM group was not supported in our study design. Our findings encourage the implementation of arterial stiffness and function measurements in daily clinical routine in high cardiovascular risk patients with CAD and T2DM.

\section{Conflict of Interest}

Dr. Illyés is an owner of TensioMed Ltd., a company that designs and manufactures devices that measure vascular stiffness.

\section{Acknowledgements}

This study was supported by the Hungarian National Research Foundation (OTKA) No. 78480.

\section{References}

BAULMANN J, SCHILLINGS U, RICKERT S, UEN S, DÜSING R, ILLYES M, CZIRAKI A, NICKERING G, MENGDEN T: A new oscillometric method for assessment of arterial stiffness: comparison with tonometric and piezo-electronic methods. J Hypertens 26: 523-528, 2008.

BOUTOUYRIE P, TROPEANO AI, ASMAR R, GAUTIER I, BENETOS A, LACOLLEY P, LAURENT S: Aortic stiffness is an independent predictor of primary coronary events in hypertensive patients: a longitudinal study. Hypertension 39: 10-15, 2002.

BOUTOUYRIE P, REVERA M, PARATI G: Obtaining arterial stiffness indices from simple arm cuff measurements: the holy grail? J Hypertens 27: 2159-2161, 2009.

BOUTOUYRIE P, LACOLLEY P, BRIET M, REGNAULT V, STANTON A, LAURENT S, MAHMUD A: Pharmacological modulation of arterial stiffness. Drugs 71: 1689-1701, 2011.

D'AGOSTINO RB SR, VASAN RS, PENCINA MJ, WOLF PA, COBAIN M, MASSARO JM, KANNEL WB: General cardiovascular risk profile for use in primary care: the Framingham Heart Study. Circulation 117: 743-753, 2008.

DOI M, MIYOSHI T, HIROHATA S, KAMIKAWA S, USUI S, KAJI Y, SAKANE K, OGAWA H, NINOMIYA Y, KUSACHI S: Combination therapy of calcium channel blocker and angiotensin II receptor blocker reduces augmentation index in hypertensive patients. Am J Med Sci 339: 433-439, 2010.

ESC Guidelines on diabetes, pre-diabetes, and cardiovascular diseases developed in collaboration with the EASD: The Task Force on diabetes, pre-diabetes, and cardiovascular diseases of the European Society of Cardiology (ESC) and developed in collaboration with the European Association for the Study of Diabetes (EASD). Eur Heart J 34: 3035-3087, 2013.

2013 ESC guidelines on the management of stable coronary artery disease: The Task Force on the management of stable coronary artery disease of the European Society of Cardiology. Eur Heart J 34: 2949-3003, 2013.

HAFFNER SM, LEHTO S, RÖNNEMAA T, PYÖRÄLÄ K, LAAKSO M: Mortality from coronary heart disease in subjects with type 2 diabetes and in nondiabetic subjects with and without prior myocardial infarction. $N$ Engl J Med 339: 229-234, 1998.

HANSSON GK: Inflammation, atherosclerosis, and coronary artery disease. N Engl J Med 352: 1685-1695, 2005.

HORVÁTH IG, NÉMETH A, LENKEY Z, ALESSANDRI N, TUFANO F, KIS P, GASZNER B, CZIRÁKI A: Invasive validation of a new oscillometric device (Arteriograph) for measuring augmentation index, central blood pressure and aortic pulse wave velocity. J Hypertens 28: 2068-2075, 2010.

JATOI NA, MAHMUD A, BENNETT K, FEELY J: Assessment of arterial stiffness in hypertension: comparison of oscillometric (Arteriograph), piezoelectronic (Complior) and tonometric (SphygmoCor) techniques. J Hypertens 27: 2186-2191, 2009.

KHOSHDEL AR, CARNEY SL: Increased pulse wave velocity is not associated with elevated augmentation index in patients with diabetes. J Hypertens 23: 669-670, 2005. 
KULLO IJ, BIELAK LF, TURNER ST, SHEEDY PF 2ND, PEYSER PA: Aortic pulse wave velocity is associated with the presence and quantity of coronary artery calcium: a community-based study. Hypertension 47: 174-179, 2006.

LACY PS, O’BRIEN DG, STANLEY AG, DEWAR MM, SWALES PP, WILLIAMS B: Increased pulse wave velocity is not associated with elevated augmentation index in patients with diabetes. J Hypertens 22: 1937-1944, 2004.

LAURENT S, BOUTOUYRIE P, ASMAR R, GAUTIER I, LALOUX B, GUIZE L, DUCIMETIERE P, BENETOS A: Aortic stiffness is an independent predictor of all-cause and cardiovascular mortality in hypertensive patients. Hypertension 37: 1236-1241, 2001.

LAURENT S, COCKCROFT J, VAN BORTEL L, BOUTOUYRIE P, GIANNATTASIO C, HAYOZ D, PANNIER B, VLACHOPOULOS C, WILKINSON I, STRUIJKER-BOUDIER H; EUROPEAN NETWORK FOR NONINVASIVE INVESTIGATION OF LARGE ARTERIES: Expert consensus document on arterial stiffness: methodological issues and clinical applications. Eur Heart J 27: 2588-2605, 2006.

MAHMUD A, FEELY J: Beta-blockers reduce aortic stiffness in hypertension but nebivolol, not atenolol, reduces wave reflection. Am J Hypertens 21: 663-667, 2008.

MALLAREDDY M, PARIKH CR, PEIXOTO AJ: Effect of angiotensin-converting enzyme inhibitors on arterial stiffness in hypertension: systematic review and meta-analysis. J Clin Hypertens 8: 398-403, 2006.

MANISTY C, MAYET J, TAPP RJ, SEVER PS, POULTER N, MCG THOM SA, HUGHES AD; ASCOT INVESTIGATORS: Atorvastatin treatment is associated with less augmentation of the carotid pressure waveform in hypertension: a substudy of the Anglo-Scandinavian Cardiac Outcome Trial (ASCOT). Hypertension 54: 1009-1013, 2009.

MATTACE-RASO FU, VAN DER CAMMEN TJ, HOFMAN A, VAN POPELE NM, BOS ML, SCHALEKAMP MA, ASMAR R, RENEMAN RS, HOEKS AP, BRETELER MM, WITTEMAN JC: Arterial stiffness and risk of coronary heart disease and stroke: the Rotterdam Study. Circulation 113: 657-663, 2006.

NAGY G, GASZNER B, LÁNYI É, MARKÓ L, FEHÉR E, CSEH J, KŐSZEGI T, BETLEHEM J, SULYOK E, CZIRÁKI A, WITTMANN I: Selective association of endogenous ouabain with subclinical organ damage in treated hypertensive patients. J Hum Hypertens 25: 122-129, 2011.

NAJJAR SS, SCUTERI A, LAKATTA EG: Arterial aging: is it an immutable cardiovascular risk factor? Hypertension 46: 454-462, 2005.

OGAWA O, HIRAOKA K, WATANABE T, KINOSHITA J, KAWASUMI M, YOSHII H, KAWAMORI R: Diabetic retinopathy is associated with pulse wave velocity, not with the augmentation index of pulse waveform. Cardiovasc Diabetol 7: 11, 2008.

REFERENCE VALUES FOR ARTERIAL STIFFNESS' COLLABORATION: Determinants of pulse wave velocity in healthy people and in the presence of cardiovascular risk factors: 'establishing normal and reference values'. Eur Heart J 31: 2338-2350, 2010.

SUGAWARA J, HAYASHI K, YOKOI T, TANAKA H: Age-associated elongation of the ascending aorta in adults. JACC Cardiovasc Imaging 1: 739-748, 2008.

VAN BORTEL LM, LAURENT S, BOUTOUYRIE P, CHOWIENCZYK P, CRUICKSHANK JK, DE BACKER T, FILIPOVSKY J, HUYBRECHTS S, MATTACE-RASO FU, PROTOGEROU AD, SCHILLACI G, SEGERS P, VERMEERSCH S, WEBER T; ARTERY SOCIETY; EUROPEAN SOCIETY OF HYPERTENSION WORKING GROUP ON VASCULAR STRUCTURE AND FUNCTION; EUROPEAN NETWORK FOR NONINVASIVE INVESTIGATION OF LARGE ARTERIES: Expert consensus document on the measurement of aortic stiffness in daily practice using carotid-femoral pulse wave velocity. J Hypertens $\mathbf{3 0}$ : 445-448, 2012.

WEBER T, AUER J, O'ROURKE MF, KVAS E, LASSNIG E, BERENT R, EBER B: Arterial stiffness, wave reflections, and the risk of coronary artery disease. Circulation 109: 184-189, 2004.

WESTERBACKA J, UOSUKAINEN A, MÄKIMATTILA S, SCHLENZKA A, YKI-JÄRVINEN H: Insulin-induced decrease in large artery stiffness is impaired in uncomplicated type 1 diabetes mellitus. Hypertension 35 : 1043-1048, 2000. 
WILLUM-HANSEN T, STAESSEN JA, TORP-PEDERSEN C, RASMUSSEN S, THIJS L, IBSEN H, JEPPESEN J: Prognostic value of aortic pulse wave velocity as index of arterial stiffness in the general population. Circulation 113: 664-670, 2006.

WOODMAN RJ, WATTS GF: Measurement and application of arterial stiffness in clinical research: focus on new methodologies and diabetes mellitus. Med Sci Monit 9: RA81-RA89, 2003.

ZHANG M, BAI Y, YE P, LUO L, XIAO W, WU H, LIU D: Type 2 diabetes is associated with increased pulse wave velocity measured at different sites of the arterial system but not augmentation index in a Chinese population. Clin Cardiol 34: 622-627, 2011. 